\title{
Capturing a moving target: interviewing fintech experts via LinkedIn
}

Gary Robinson

Department of Urban Development and Mobility, Luxembourg Institute of SocioEconomic Research (LISER), Esch-sur-Alzette/Belval, Luxembourg

Department of Geography and Spatial Planning, University of Luxembourg, Esch-surAlzette/Belval, Luxembourg

Department of Geography, Ghent University, Ghent, Belgium

ORCID: 0000-0002-7582-2557

gary.robinson@liser.lu

This is the submitted version of an article first published by Wiley in Area on 15th May 2021, available at: https://doi.org/10.1111/area.12726.

Date accepted: $6^{\text {th }}$ May 2021

\section{ACKNOWLEDGEMENTS}

I wish to thank Sabine Dörry, Ben Derudder and two reviewers for their comments. I am grateful to all research participants. This work was supported by the Research Foundation - Flanders (FWO) and the Luxembourg National Research Fund (FNR) (INTER/FWO/16/11312037/FinWebs).

\section{DATA AVAILABILITY}

For confidentiality reasons, interview transcripts from the research project concerned are not publicly available. 


\title{
Capturing a moving target: interviewing fintech experts via LinkedIn
}

\begin{abstract}
This paper explores possible responses to some of the main challenges associated with conducting elite and expert interviews as part of qualitative research in human geography. Drawing on the example of the dynamic fintech industry, the paper outlines some similarities and differences between elite and expert interviews, and uses this to identify and discuss possible responses. Against this backdrop, the paper also reflects on advantages and disadvantages of using the professional social networking site LinkedIn as a research aid for sampling and contacting interviewees as well as for interview preparation. The paper is anticipated to be of interest to those conducting qualitative research involving limited subject sample sizes who are potentially difficult to find.
\end{abstract}

\section{KEYWORDS}

elite and expert interviews, qualitative research methods, financial geography, fintech, LinkedIn, social networking service

\section{INTRODUCTION}

The paper reflects on some methodological challenges experienced while conducting elite and expert interviews as part of qualitative research in human geography and on the practical responses to these challenges. The importance of interviews as a key qualitative research method has been long recognised across different disciplines, such as political science (Richards, 1996), sociology (Ostrander, 1993), and business studies (Yeung, 1995) and there is a wealth of work by geographers (Desmond, 2004; Harvey, 2011; Herod, 1999; James, 2006; McDowell, 1998; Schoenberger, 1991; Smith, 2006). Much literature provides guidance on the factors, skills and preparation necessary to successfully obtain and analyse data from such interviews. Qualitative researchers continually adapt and reflect on their methods in specific fields and environments (McFarlane-Morris, 2020) and on their use of new technological tools (Adams-Hutcheson \& Longhurst, 2017; Truong et al., 2020). However, despite the benefits of such tools for conducting and analysing interviews, as well as for sampling and preparation, some perennial problems persist, perhaps the most enduring of which is gaining access to interviewees.

Previous research shows that although elites may in fact often be willing to share their experiences, reaching them is the key problem (Delaney, 2007; Mikecz, 2012; Useem, 1995). While some feel that difficulties gaining access are exaggerated (Ostrander, 1993), many researchers have provided valuable practical information on their experiences of 'getting in the door' (Goldstein, 2002, p. 669). Pre-interview preparation is paramount, as is gaining trust and building rapport (Mikecz, 2012), which researchers can achieve through being honest and transparent about themselves, their research goals, research dissemination, the interview process, and information attribution and interviewee anonymity (Goldstein, 2002; Harvey, 2011; Lilleker, 2003). To gain access, scholars are recommended to make use of their institutional affiliation, to leverage personal networks, and to consider getting project endorsement from an influential 
sponsor (Aberbach \& Rockman, 2002). Others have noted specificities of gaining access to elites in different cultural contexts (Liu, 2018; Mikecz, 2012) as well as the impact of gender differences when conducting interviews (Desmond, 2004; Herod, 1993; McDowell, 1998) in the 'indelibly male-dominated habitats' of industry and institutional elites (Wong, 2018, p. 13). However, gaining access is often contingent upon opportunism, fortune, circumstance and personal connections (McDowell, 1998; Ostrander, 1993; Parry, 1998; Yeung, 1995).

Although researchers can still draw upon insights in the extant literature, recommendations to contact interviewees by post, fax or cold calling by telephone (Delaney, 2007; Thomas, 1995; Useem, 1995; Yeung, 1995) now seem dated. More recent literature replaces letters with emails, and some research mentions the use of public online directories for locating interviewees (e.g. Lilleker, 2003). Professional social networking platforms like LinkedIn are overlooked in recent work on the topic of social media in qualitative research (McKenna, Myers, \& Newman, 2017; Sloan \& Quan-Haase, 2017; Snelson, 2016). Offering a corporate directory with granular search, user profiles, and a channel to contact many professionals across multiple geographies, LinkedIn presents a potentially useful avenue for qualitative researchers to deal with the abiding problems of sampling, gaining access and interview preparation (Dicce \& Ewers, 2020). This may be even more salient when researching industries and organisations that present particular access difficulties.

\section{RESEARCHING FINANCE}

\subsection{The research project}

The context for this paper is a doctoral research project on innovation in financial technology (fintech). The finance industry projects a dual aura of 'sexy and arcane' (Leyshon \& Thrift, 1997, p. 191). Some investment banking and trading activities have been simultaneously glamorised and made notorious in popular media such as films like The Wolf of Wall Street and the books of Michael Lewis. However, most financial workers are employed in more ordinary middle- and back-office support roles or in retail and commercial banking, some of whom are paid comparatively much less than frontoffice workers.

One such area is that of financial infrastructure, including payment systems, which is essential for economic activity and involves specialist technological and organisational knowledge. The area of payments seldom saw change, until technological innovation after the financial crisis of 2008 brought a rare opportunity for disruption by non-financial actors using novel technologies such as blockchain. The project explores how change materialises in and between organisations, and in the global network of international financial centres. The methodology is one of semi-structured interviews with people working mainly in financial institutions and financial technology firms. The research revolved mainly around a financial infrastructure cooperative but also involved other organisations, including: innovation and payments departments at banks; finance industry consortia; financial technology system integrators; fintech firms; and payments departments at non-bank firms.

Quantitative methods dominate and define research into finance in fields specialising in the area (Kaczynski, Salmona, \& Smith, 2014), with qualitative research considered rare and of unproven credibility by some within those fields (Gippel, 2012). 
However, social scientists from fields such as anthropology (e.g. Ho, 2009; Luyendijk, 2016; Zaloom, 2010) and geography (e.g. Dörry, 2015; Hall, 2009; McDowell, 1997), have long used qualitative methods, including interviews, to provide rich insights into finance, in which as an information industry, 'close dialogue is an essential ingredient' (Clark, 1998, p. 82).

\subsection{A secretive and complex industry}

Both the finance industry and the research project present some methodological challenges as objects of qualitative research. Researchers have noted difficulties finding and gaining access to potential interviewees because 'the world of finance is governed by a code of silence' (Luyendijk, 2016, p. 13). This may be partly because of negative publicity and suspicion of the industry, for example because of cases of corporate misconduct, the perceived role in causing financial crises, and sometimes very high remuneration.

The case at hand involves studying a relatively small number of key organisations operating in the area of payments. Gaining access to interviewees at all organisations proved to be difficult. This could be because of the aforementioned characteristics of the financial industry but also because co-operative ownership and governance of some financial organisations in some respects functions like a club in providing exclusive rules and benefits to members (Potoski \& Prakash, 2009) and in serving as a private forum (Tsingou, 2015). Informants' desire and ability to respond to requests for interview may have been limited by the sensitive nature of the technology and collaborations, in some cases involving national central banks and large systemically important financial institutions, and perhaps also because of some firms' sensitivity about public image. Additionally, increasing requests from researchers for interviews demands more of interviewees' time for little in return.

A further problem is the industry's complexity. Banks can be large organisations, with many different departments and functions, which may be siloed, with little connection to each other, and staffed by individuals with distinct personalities, dispositions, interests and experiences. Some departments may be more or less collaborative with other internal departments and external organisations, and therefore more knowledgeable and open, and this may condition how employees respond to interview requests. Additionally, some of the new technologies and actors exist since just 2008, only beginning to achieve widespread consciousness in mainstream finance around 2015. The pace of change since then has been dizzying, presenting challenges in keeping up with change, delimiting the research, and understanding the technologies' workings.

\section{ELITE AND EXPERT INTERVIEWS}

Mirroring the duality of the finance industry mentioned above, there is a distinction between elite and expert interviews. Anglo-American literature focuses almost exclusively on elite interviews, while German-language literature talks mostly about expert interviews (Littig, 2009). This has an interesting historical parallel in Landes' (1969) distinction between the 'pecuniary rationality' of British business and the 'technological rationality' of German business. 
Because elites are often only vaguely specified in methodology literature, Welch et al.'s (2002, p. 613) precise definition of a corporate elite interviewee is worth quoting in full:

an informant (usually male) who occupies a senior or middle management position; has functional responsibility in an area which enjoys high status in accordance with corporate values; has considerable industry experience and frequently also long tenure with the company; possesses a broad network of personal relationships; and has considerable international exposure.

While this interpretation is notably not limited to senior management, the defining points of elites generally concern power, authority and status, with a presumption that their access to high level knowledge makes them suitable for interview (Van Audenhove \& Donders, 2019). Experts have been broadly defined as those responsible for the implementation or control of problem solving, and those with privileged access to information about people or decision-making processes (Littig, 2009). Experts thus hold knowledge not otherwise available to researchers and are often also in positions of power but not necessarily top leadership. While big shots, or visible elites, may seem like the first and most obvious interviewees, as well as being shielded and very busy, they may not have the specific knowledge needed (Van Audenhove \& Donders, 2019). Elites' and experts' different roles and responsibilities, generalisable as more strategic for the former and operational for the latter, yield different kinds of information for different purposes. Elites' social capital could be more likely to result in other interviews via snowballing. In a context where technology is driving change and banks are becoming more like tech firms, particular experts may also have strategic knowledge, while the increased "technicalisation" of finance as an information industry elevates the importance of expert knowledge. The conception of expert can reasonably be decoupled from hierarchical occupational status position (Meuser \& Nagel, 2009) and this consequently widens the pool of people considered to be useful informants beyond elites. Corporate elites may be 'visible but not accessible' (Thomas, 1995, p. 4), with deliberate barriers making them hard to study (Hertz \& Imber, 1995, p. viii), however experts can be both invisible and inaccessible.

\section{GAINING ACCESS: THE SONG REMAINS THE SAME}

\subsection{Sampling}

Gaining access is a perennial problem comprising multiple overlapping processes, such as sampling, pitching, and interviewing. Focussed recruitment methods are needed for select populations. These include tried and trusted methods like: leveraging personal connections (Welch et al., 2002); industry conference programmes, even if not actually attending the event; snowballing; and desk research (Van Audenhove \& Donders, 2019). Professional networking websites are a compelling tool for sampling. Apart from some location- and industry-specific sites, LinkedIn offers global, cross-industry coverage and serves as a powerful way of finding interviewees, featuring granular search by industry, current and previous employer, geographic location and skill (Dicce \& Ewers, 2020). More refined sample inclusion criteria can be gleaned from career biographies, also useful during interview preparation, while job titles, roles and tasks can assist with learning more about the organisation structure of firms and with identifying experts with cross-domain knowledge. Searching for profiles also sometimes shows other related and interesting 
profiles. The platform's refined search options allow external sampling, or 'the inclusion of interviewees outside the focal organisation but with knowledge of it' (Welch et al., 2002, p. 624), such as customers and former employees of target organisations. I conducted twice as many interviews with experts compared to elites. Elites are obviously fewer in number and were less likely to respond to requests for interview. LinkedIn's granular search allowed targeting of an expanded pool of potential respondents while also learning about organisation structures and the wider array of roles in work areas.

Methods for identifying elite subjects interviewed were fairly evenly spread across personal network, desk research, and in-person introduction at a conference. The most successful method was conference and event programmes, including online events. Interestingly, not one of the elite subjects interviewed was initially identified on LinkedIn, nor were any found through snowballing. While many elite potential interviewees were found on LinkedIn, none replied to interview requests. Of the expert interviews conducted, LinkedIn was the avenue via which almost half of the participants were found. The next most successful method was conference and event programmes, both live and online, with the remainder fairly evenly split between personal networks, snowballing and desk research. While snowballing, or asking interviewees to recommend others, is acknowledged as a good way to find participants, it has limits (Waters, 2015). Certain organisations may present particular challenges and even a personal referral by email from another interviewee did not guarantee a response. I eventually interviewed two elite and one expert subjects at the organisation in question, introduced via personal network, snowballing, and LinkedIn message mentioning an online conference which the recipient had taken part in. Just as certain organisations may present challenges, certain roles may be more amenable to snowballing. This I found to be the case among some tech employees, who are used to collaborating and sharing online with other tech enthusiasts outside of work, and who collaborate with fintech and other partners in work. In sum, LinkedIn complements established sampling methods and is especially useful for finding expert and less visible participants, but the serendipity of introductions via personal networks remains important.

\subsection{Pitching and relying on gatekeepers}

Having identified potential interviewees, contacting and gaining access is the next challenge. Reliance on gatekeepers when accessing elite interviewees is well documented (Campbell, Gray, Meletis, Abbott, \& Silver, 2006), however experts' relative anonymity within large organisations is also a barrier, one which LinkedIn, as explained above, is useful for surmounting. LinkedIn is now an alternative to corporate directories and it has become practically the only game in town for contacting people. Corporate websites rarely list professionals' email addresses and some even link directly to employees' LinkedIn profile pages. Practically all subjects are on LinkedIn and contact requests are thus necessarily also pitched via the platform. The same content and caveats as when sending emails apply (Delaney, 2007), however, LinkedIn's character limits forces brevity. Replies and subsequent messages may be very short, more akin to a messaging app, given users often use it on phones, rather than solely on computers. Just over half of the total successful contact requests I sent were via LinkedIn, with the remainder via email. Of those sent by email, none of the email addresses were publicly available, found instead via personal network or snowballing referral, obtained at a conference, or in reply to a contact request submitted via a webform. LinkedIn's importance as a contact medium is thus enhanced when contact information is almost never public. 
On one hand LinkedIn democratises access by allowing direct connection with a wider network of potential interviewees, circumventing human gatekeepers and a lack of publicly available contact information (Dicce \& Ewers, 2020). However, in some respects, LinkedIn has become an electronic gatekeeper, one whose mercy cannot be appealed to. Assuming that users manage their own profiles, they can ignore messages and connection requests, and can choose not to receive messages from unknown people. Initial contact on LinkedIn sometimes results in being asked to contact the participant via email, however this is still no guarantee of actually getting an interview, as such emails may then go unanswered. An additional barrier is that of cost. Free LinkedIn membership allows sending only very few messages per month, has limitations on searching and viewing profiles, and does not allow a user to hide from users that they viewed a profile. Effective use of LinkedIn's features, such as the ability to send more messages, unlimited profile search, and "invisible" profile browsing, depends on premium membership, which is free for the first month, with subsequent varying levels of premium membership costing non-inconsiderate monthly or annual fees. As with other digital platforms, LinkedIn may be more reintermediation than disintermediation (Langley \& Leyshon, 2020).

\subsection{Interviewing}

LinkedIn's gatekeeper role is also important with respect to user profiles and positionality. Researcher positionality is both elastic and dynamic, changing depending on the interviewee and over the course of research (Mason-Bish, 2018; Mikecz, 2012; Rice, 2010), with both interviewer and interviewee constructing distinct versions of themselves in interviews (Clark, 1998; McDowell, 1992). Social media platforms 'are not neutral stages of self-performance' (van Dijck, 2013, p. 213) but are one way in which interviewers can 'construct themselves as certain types-of-people in relation to the topic of the interview and reflexively the interview itself' (Rapley, 2016, p. 303). Some scholars recommend an "insider" business-like approach to reduce the professional gap between the researcher and elite interviewees (Welch et al., 2002; Yeung, 1995), while others have found that using LinkedIn often changed their positionality by 'blurring the insider/outsider industry dynamic' (Dicce \& Ewers, 2020, p. 7). However, without industry experience and expertise, and given the club-like nature of finance, it is unclear how a researcher might be able to feel like an insider. LinkedIn profile visibility works both ways. Researchers can unobtrusively scan potential interviewees' profiles but the researcher's profile may be decisive in whether a respondent, particularly if unaccustomed to receiving interview requests, decides whether to participate (Dicce \& Ewers, 2020). For the researcher, having an adequate level of knowledge of a specialist research topic is important to avoid not being taken seriously, but also to avoid wasting valuable interview time on basic concepts. The profile can at least be a place to signal a certain level or area of knowledge. There are LinkedIn groups for those interested in particular speciality areas, and membership may demonstrate interest in or knowledge of the area to a potential interviewee. Additionally, LinkedIn premium membership may also send a positive and professional signal for other site users, while visibility of common contacts may generate trust and influence interviewees' decisions to respond to an interview request.

Certain interviews yield more useful information than others, and for my research, I classified interviews as being useful in strategic terms or operational terms, roughly corresponding to the distinction between elites and experts. While I interviewed twice as many experts as elites, expert interviews were around four times more likely to be useful, compared to elite interviews, in terms of both strategy and operations. For elites, the most 
useful were found via desk research, where they had been interviewed for industry news articles, and were contacted via LinkedIn. These interviews were conducted via phone or video, and the interviewees currently or previously worked in finance. Among the most useful expert interviews, introductions via personal network and snowballing accounted for a quarter, while the remainder were found by searching on LinkedIn. Despite being classed as expert interviews, most of these were also useful in terms of strategy. Just over half of these were conducted by phone and the remainder in person. Almost half of them were either former employees of organisations key for the research or former employees of customers of those organisations, while another worked at a smaller firm that worked closely with key organisations. I was fortunate to have finished fieldwork just before the COVID-19 pandemic of early 2020, but over half of the most useful interviews were not conducted in-person. Although considered suspect, phone interviews provide researchers with the benefits of flexibility and access unavailable in other ways (Block \& Erskine, 2012). Neither elite/expert status nor LinkedIn may provide an advantage when it comes to repeated interactions as part of close dialogue. Most respondents provided an email address following initial contact on LinkedIn and the likelihood of responses to subsequent communication seemed more related to the kind of respondent (Clark, 1998).

Elites know they are elites and are therefore used to receiving interview requests from both media and academia, and may be adept at "performing" interviews, for example giving evasive answers to difficult questions. They may also be bound by internal organisation policies regarding giving interviews. Having successfully navigated the LinkedIn gatekeeper, researchers must still be prepared to deal with human gatekeepers, such as public relations representatives and staff, and conditions like NDAs or seeking approval prior to publication of any interview insights used. On the other hand, experts may not even realise they are experts. They may therefore be less accustomed to being approached for interview and may be surprised that someone is interested in what they do and in their specialised knowledge. LinkedIn's search features help to render experts more visible, and to conduct targeted searches by employment history, skills and expertise. This is a very powerful tool for researchers, especially for finding informants who are perhaps no longer bound by commitments to a current employer. The realities of trying to access elites can prompt a pragmatic decision to enlarge the pool of research participants, but some experts have what might be considered more elite-level knowledge, as well as being willing and able to share it. Considering experts as valuable research participants helps move beyond privileging elites as the main sources of insider knowledge.

\section{CONCLUSION}

There are far more similarities than differences between elite and expert interviews. Being mindful of both can help with sampling and with interview preparation and execution, and may also help with "demystifying" elites and perceived power differentials. Ultimately, the researcher is the arbiter of sample size and of what is an elite or expert interview. The LinkedIn platform combines multiple elements: a searchable corporate directory, user profiles, and messaging medium. For qualitative research into the corporate world, it is a valuable resource for finding, contacting and preparing to meet with more visible elite and especially with less visible expert interviewees. However, alongside newer digital tools, longstanding techniques remain crucial. While LinkedIn offers potential access to a larger pool of interviewees, there is still no guarantee that they will agree to participate. In the absence of personal connections and apart from industry and organisation-specific factors, this leaves researchers largely still reliant on elements 
like luck, timing and respondent disposition, to get in the (sometimes virtual) door, making it still 'more art than science' (Goldstein, 2002, p. 669). Having certain things in common with interviewees, for example gender (Desmond, 2004; McDowell, 1998), cannot be taken for granted as a way to build rapport but surprising elements of a researcher's background and profile can be persuasive. A useful empirical project, alongside "actual" research, would be to try to understand the elements of a researcher's LinkedIn profile that induce interviewees to participate, for example, affiliation, connections to other platform users, skills, endorsements, group membership, or indeed how much attention was even paid to the researcher's profile. Frustration, failures and mishaps are as much part and parcel of fieldwork as its joys of connections and moments of intellectual insight (McSweeney \& WinklerPrins, 2020). While there is still sometimes a trade-off between who you want and who you can get, the above insights could help researchers to better use both traditional and newer avenues artfully to try to create good fortune.

\section{REFERENCES}

Aberbach, J. D., \& Rockman, B. A. (2002). Conducting and Coding Elite Interviews. PS: Political Science and Politics, 35(4), 673-676. https://doi.org/10.1017/S1049096502001142

Adams-Hutcheson, G., \& Longhurst, R. (2017). 'At least in person there would have been a cup of tea': Interviewing via Skype. Area, 49(2), 148-155. https://doi.org/10.1111/area.12306

Block, E. S., \& Erskine, L. (2012). Interviewing by Telephone: Specific Considerations, Opportunities, and Challenges. International Journal of Qualitative Methods, 11(4), 428-445. https://doi.org/10.1177/160940691201100409

Campbell, L. M., Gray, N. J., Meletis, Z. A., Abbott, J. G., \& Silver, J. J. (2006). Gatekeepers and Keymasters: Dynamic Relationships of Access in Geographical Fieldwork. Geographical Review, 96(1), 97-121. https://doi.org/10.1111/j.19310846.2006.tb00389.x

Clark, G. L. (1998). Stylized Facts and Close Dialogue: Methodology in Economic Geography. Annals of the Association of American Geographers, 88(1), 73-87. https://doi.org/10.1111/1467-8306.00085

Delaney, K. J. (2007). Methodological Dilemmas and Opportunities in Interviewing Organizational Elites. Sociology Compass, 1(1), 208-221. https://doi.org/10.1111/j.1751-9020.2007.00028.x

Desmond, M. (2004). Methodological challenges posed in studying an elite in the field. Area, 36(3), 262-269. https://doi.org/10.1111/j.0004-0894.2004.00223.x

Dicce, R. P., \& Ewers, M. C. (2020). Becoming Linked In: Leveraging Professional Networks for Elite Surveys and Interviews. Geographical Review, 110(1-2), 160-171. https://doi.org/10.1111/gere.12346

Dörry, S. (2015). Strategic nodes in investment fund global production networks: The example of the financial centre Luxembourg. Journal of Economic Geography, 15(4), 797-814. https://doi.org/10.1093/jeg/lbu031

Gippel, J. K. (2012). A revolution in finance?: Australian Journal of Management, 38(1), 125-146. (Sage UK: London, England). https://doi.org/10.1177/0312896212461034

Goldstein, K. (2002). Getting in the Door: Sampling and Completing Elite Interviews. PS: Political Science and Politics, 35(4), 669-672. 
Hall, S. (2009). Financialised Elites and the Changing Nature of Finance Capitalism: Investment Bankers in London's Financial District. Competition \& Change, 13(2), 173-189. https://doi.org/10.1179/102452909X417042

Harvey, W. S. (2011). Strategies for conducting elite interviews. Qualitative Research, 11(4), 431-441. https://doi.org/10.1177/1468794111404329

Herod, A. (1993). Gender Issues in the Use of Interviewing as a Research Method*. The Professional Geographer, 45(3), 305-317. https://doi.org/10.1111/j.00330124.1993.00305.x

Herod, A. (1999). Reflections on interviewing foreign elites: Praxis, positionality, validity, and the cult of the insider. Geoforum, 30(4), 313-327. https://doi.org/10.1016/S0016-7185(99)00024-X

Hertz, R., \& Imber, J. (1995). Studying Elites Using Qualitative Methods (1 edition). Thousand Oaks, Calif: SAGE Publications, Inc.

Ho, K. (2009). Liquidated: An Ethnography of Wall Street. Durham: Duke University Press Books.

James, A. (2006). Critical moments in the production of 'rigorous' and 'relevant' cultural economic geographies. Progress in Human Geography, 30(3), 289-308. https://doi.org/10.1191/0309132506ph610oa

Kaczynski, D., Salmona, M., \& Smith, T. (2014). Qualitative research in finance. Australian Journal of Management, 39(1), 127-135. https://doi.org/10.1177/0312896212469611

Landes, D. S. (1969). The Unbound Prometheus: Technological Change and Industrial Development in Western Europe from 1750 to the Present. Cambridge, UK ; New York: Cambridge University Press.

Langley, P., \& Leyshon, A. (2020). The Platform Political Economy of FinTech: Reintermediation, Consolidation and Capitalisation. New Political Economy, O(0), 1-13. https://doi.org/10.1080/13563467.2020.1766432

Leyshon, A., \& Thrift, N. (1997). Money/Space: Geographies of Monetary Transformation. London; New York: Routledge.

Lilleker, D. G. (2003). Interviewing the Political Elite: Navigating a Potential Minefield. Politics, 23(3), 207-214. https://doi.org/10.1111/1467-9256.00198

Littig, B. (2009). Interviewing the Elite - Interviewing Experts: Is There a Difference? In A. Bogner, B. Littig, \& W. Menz (Eds.), Interviewing Experts (pp. 98-113). Basingstoke: Palgrave Macmillan.

Liu, X. (2018). Interviewing Elites: Methodological Issues Confronting a Novice. International Journal of Qualitative Methods, 17(1), 1-9. https://doi.org/10.1177/1609406918770323

Luyendijk, J. (2016). Swimming with Sharks: Inside the World of the Bankers. Guardian Faber Publishing.

Mason-Bish, H. (2018). The elite delusion: Reflexivity, identity and positionality in qualitative research: Qualitative Research. (Sage UK: London, England). https://doi.org/10.1177/1468794118770078

McDowell, L. (1992). Valid Games? A Response to Erica Schoenberger. The Professional Geographer, 44(2), 212-215. https://doi.org/10.1111/j.00330124.1992.00212.x

McDowell, L. (1997). Capital Culture: Gender at Work in the City. Oxford, UK; Malden, Mass: John Wiley \& Sons.

McDowell, L. (1998). Elites in the City of London: Some Methodological Considerations. Environment and Planning A: Economy and Space, 30(12), 2133-2146. https://doi.org/10.1068/a302133 
McFarlane-Morris, S. (2020). "Home sweet home?” Struggles of intracultural "betweenness" of doctoral fieldwork in my home country of Jamaica. Area, 52(2), 394-400. https://doi.org/10.1111/area.12580

McKenna, B., Myers, M. D., \& Newman, M. (2017). Social media in qualitative research: Challenges and recommendations. Information and Organization, 27(2), 87-99. https://doi.org/10.1016/j.infoandorg.2017.03.001

McSweeney, K., \& WinklerPrins, A. (2020). Introduction to the Special Issue: Fieldwork in the 21st Century. Geographical Review, 110(1-2), 1-7. https://doi.org/10.1080/00167428.2019.1689361

Meuser, M., \& Nagel, U. (2009). The Expert Interview and Changes in Knowledge Production. In A. Bogner, B. Littig, \& W. Menz (Eds.), Interviewing Experts (pp. 17-42). Basingstoke: Palgrave Macmillan.

Mikecz, R. (2012). Interviewing Elites: Addressing Methodological Issues. Qualitative Inquiry, 18(6), 482-493. https://doi.org/10.1177/1077800412442818

Ostrander, S. A. (1993). "Surely you're not in this just to be helpful": Access, Rapport, and Interviews in Three Studies of Elites. Journal of Contemporary Ethnography, 22(1), 7-27. https://doi.org/10.1177/089124193022001002

Parry, B. (1998). Hunting the Gene-Hunters: The Role of Hybrid Networks, Status, and Chance in Conceptualising and Accessing 'Corporate Elites'. Environment and Planning A: Economy and Space, 30(12), 2147-2162. https://doi.org/10.1068/a302147

Potoski, M., \& Prakash, A. (Eds.). (2009). Voluntary programs: A club theory perspective. Cambridge, Mass.: MIT Press.

Rapley, T. J. (2016). The art(fulness) of open-ended interviewing: Some considerations on analysing interviews. Qualitative Research, 1(3), 303-323. (Sage CA: Thousand Oaks, CA). https://doi.org/10.1177/146879410100100303

Rice, G. (2010). Reflections on interviewing elites. Area, 42(1), 70-75. https://doi.org/10.1111/j.1475-4762.2009.00898.x

Richards, D. (1996). Elite Interviewing: Approaches and Pitfalls. Politics, 16(3), 199204. https://doi.org/10.1111/j.1467-9256.1996.tb00039.x

Schoenberger, E. (1991). The Corporate Interview as a Research Method in Economic Geography. The Professional Geographer, 43(2), 180-189. https://doi.org/10.1111/j.0033-0124.1991.00180.x

Sloan, L., \& Quan-Haase, A. (Eds.). (2017). The SAGE Handbook of Social Media Research Methods. Los Angeles ; London: SAGE Publications Ltd.

Smith, K. E. (2006). Problematising power relations in 'elite' interviews. Geoforum, 37(4), 643-653. https://doi.org/10.1016/j.geoforum.2005.11.002

Snelson, C. L. (2016). Qualitative and Mixed Methods Social Media Research: A Review of the Literature. International Journal of Qualitative Methods, 15(1), 1-15. (Sage CA: Los Angeles, CA). https://doi.org/10.1177/1609406915624574

Thomas, R. J. (1995). Interviewing Important People in Big Companies. In R. Hertz \& J. Imber (Eds.), Studying Elites Using Qualitative Methods (1 edition, pp. 3-17). Thousand Oaks, Calif: SAGE Publications, Inc.

Truong, J., Labhart, F., Santani, D., Gatica-Perez, D., Kuntsche, E., \& Landolt, S. (2020). The emotional entanglements of smartphones in the field: On emotional discomfort, power relations, and research ethics. Area, 52(1), 81-88. https://doi.org/10.1111/area.12548

Tsingou, E. (2015). Club governance and the making of global financial rules. Review of International Political Economy, 22(2), 225-256. https://doi.org/10.1080/09692290.2014.890952 
Useem, M. (1995). Reaching Corporate Executives. In R. Hertz \& J. Imber (Eds.), Studying Elites Using Qualitative Methods (1 edition, pp. 18-39). Thousand Oaks, Calif: SAGE Publications, Inc.

Van Audenhove, L., \& Donders, K. (2019). Talking to People III: Expert Interviews and Elite Interviews. In H. Van Den Bulck, M. Puppis, \& K. Donders (Eds.), The Palgrave Handbook of Methods for Media Policy Research (pp. 179-197). Cham: Palgrave Macmillan.

van Dijck, J. (2013). 'You have one identity': Performing the self on Facebook and LinkedIn. Media, Culture \& Society, 35(2), 199-215. https://doi.org/10.1177/0163443712468605

Waters, J. (2015). Snowball sampling: A cautionary tale involving a study of older drug users. International Journal of Social Research Methodology, 18(4), 367-380. https://doi.org/10.1080/13645579.2014.953316

Welch, C., Marschan-Piekkari, R., Penttinen, H., \& Tahvanainen, M. (2002). Corporate elites as informants in qualitative international business research. International Business Review, 11(5), 611-628. https://doi.org/10.1016/S09695931(02)00039-2

Wong, C. M. L. (2018). Energy, Risk and Governance: The Case of Nuclear Energy in India. Palgrave Macmillan.

Yeung, H. W. (1995). Qualitative personal interviews in international business research: Some lessons from a study of Hong Kong Transnational Corporations. International Business Review, 4(3), 313-339. https://doi.org/10.1016/09695931(95)00012-O

Zaloom, C. (2010). Out of the Pits: Traders and Technology from Chicago to London (1 edition). Chicago: University of Chicago Press. 